IZA DP No. 9715

The Effects of the Minimum Wage on

Earnings Inequality: Evidence from China

Carl Lin

Myeong-Su Yun

February 2016 


\title{
The Effects of the Minimum Wage on Earnings Inequality: Evidence from China
}

\author{
Carl Lin \\ Bucknell University, \\ IZA and China Institute for Income Distribution
}

Myeong-Su Yun

Inha University

and IZA

\section{Discussion Paper No. 9715 \\ February 2016}

\author{
IZA \\ P.O. Box 7240 \\ 53072 Bonn \\ Germany \\ Phone: +49-228-3894-0 \\ Fax: +49-228-3894-180 \\ E-mail: iza@iza.org
}

Any opinions expressed here are those of the author(s) and not those of IZA. Research published in this series may include views on policy, but the institute itself takes no institutional policy positions. The IZA research network is committed to the IZA Guiding Principles of Research Integrity.

The Institute for the Study of Labor (IZA) in Bonn is a local and virtual international research center and a place of communication between science, politics and business. IZA is an independent nonprofit organization supported by Deutsche Post Foundation. The center is associated with the University of Bonn and offers a stimulating research environment through its international network, workshops and conferences, data service, project support, research visits and doctoral program. IZA engages in (i) original and internationally competitive research in all fields of labor economics, (ii) development of policy concepts, and (iii) dissemination of research results and concepts to the interested public.

IZA Discussion Papers often represent preliminary work and are circulated to encourage discussion. Citation of such a paper should account for its provisional character. A revised version may be available directly from the author. 


\section{ABSTRACT \\ The Effects of the Minimum Wage on Earnings Inequality: Evidence from China}

The minimum wage has been regarded as an important element of public policy for reducing poverty and inequality. Increasing the minimum wage is supposed to raise earnings for millions of low-wage workers and therefore lower earnings inequality. However, there is no consensus in the existing literature from industrialized countries regarding whether increasing the minimum wage has helped lower earnings inequality. China has recently exhibited rapid economic growth and widening earnings inequality. Since China promulgated new minimum wage regulations in 2004, the magnitude and frequency of changes in the minimum wage have been substantial, both over time and across jurisdictions. The growing importance of research on the relationship between the minimum wage and earnings inequality and its controversial nature have sparked heated debate in China, highlighting the importance of rigorous research to inform evidence-based policy making. We investigate the contribution of the minimum wage to the well-documented rise in earnings inequality in China over the period from 2004 to 2009 by using city-level minimum wage panel data and a representative Chinese household survey, and we find that increasing the minimum wage reduces inequality - by decreasing the earnings gap between the median and the bottom decile - over the analysis period.

JEL Classification: J31, J38, O15, R23

Keywords: minimum wage, China, earnings inequality

Corresponding author:

Carl Lin

236 Academic West

Department of Economics

Bucknell University

1 Dent Drive

Lewisburg, PA 17837

USA

E-mail: carl.lin@bucknell.edu 


\section{Introduction}

Since the reform and opening-up policy in 1978, China's economy has been growing remarkably at a rate of at least $9.5 \%$ per year. As the economy has grown, Chinese workers' earnings have also increased rapidly over the same period. According to the latest figures from the National Bureau of Statistics of China (NBS), disposable earnings per capita have risen substantially—more than 70-fold—over the past few decades in urban China, rising from 343 RMB in 1978 to 24,565 RMB in 2012, while net earnings per capita in rural China have grown 60-fold, increasing from 134 RMB in 1978 to 7,917 RMB in 2012 (National Bureau of Statistics of China 2013).

As the Chinese economy has rapidly grown, the earnings distribution has deteriorated. For example, the urban-to-rural earnings per capital ratio increased from 2.57 in 1978 to 2.90 in 2001 and further to 3.10 in 2012. The Gini coefficient, a commonly used measure of inequality, was very low level in 1978, at .16 and .22 for urban and rural areas, respectively (Li and Zhao 1999). However, as shown in Figure 1, China's overall Gini coefficient began to rise from .376 in 1988 to .439 in 1995 (Wang 2007) and increased further to .454 and .490 in 2002 and $2007^{1}$, respectively (Li and Luo 2011). In contrast, high inequality countries such as Brazil and Mexico had shown declined Gini coefficients over similar time period; whereas the U.S. was relatively stable. $^{2}$

[Figure 1 about here]

\footnotetext{
${ }^{1}$ These numbers are consistent with the official statistics published by the NBS in 2013, which also reports high inequality (for example, .484 in 2007 and .474 in 2012). The publication of these official statistics marks the first time that the Chinese government released information on the Gini coefficient. The Gini

${ }^{2}$ According to the 2015 World Development Indicators, the Gini coefficients of Brazil were .614 in 1988, .596 in 1995, .586 in 2002, then decreased to .552 and .527 in 2007 and 2012, respectively. For Mexico, the numbers decreased from .519 in 2000 to .481 in 2012. The Gini coefficient of the U.S. was .402 in 2000, increased to 416 in 2007, and slightly decreased to .411 in 2010 .
} 
The deterioration of the earnings distribution and growing gap between the rich and the poor has engendered challenges to economic development and social stability in China. As shown by the experience of developed countries, public polices, such as tax reforms, can play an essential role in countering rising inequality. Since the early 2000s, the Chinese government has intensively promulgated a series of policies, such as aid to the poor, rural minimal social security, and the minimum wage policy. Among these policy initiatives, the minimum wage policy is the most controversial. ${ }^{3}$

The contentiousness of the debate on the minimum wage policy in China arises from the difficulty of measuring its effects on employment, wages, and the earnings distribution, among others. However, the initial evidence suggests that the magnitude and frequency of changes to the minimum wage have been substantial both over time and across different jurisdictions, particularly since 2004. These large variations both across jurisdictions and over time facilitate our estimation of minimum wage effects on inequality in China. For example, in January 2004, China promulgated new minimum wage regulations that required local governments to introduce a minimum wage increase at least once every two years, that extended coverage to self-employed and part-time workers, and that quintupled the penalties for violations or noncompliance. The

\footnotetext{
${ }^{3}$ Supporters of the minimum wage in China argue that the minimum wage assists individuals or families in achieving self-sufficiency and protects workers in low-paid occupations. The minimum wage can help reduce inequality and serve as an important safety net by providing a wage floor. In addition, rising labor costs due to the minimum wage increases may promote managerial efficiency and labor productivity, inducing employers to invest in productivity-improving technology (Cooke 2005). Along these lines, many Chinese scholars have argued in favor of a more proactive increase in the minimum wage. In contrast, opponents argue that raising the minimum wage can decrease the employment opportunities of low-wage workers and lead to a reduction in other components of workers' compensation package. Such regulations can further undermine enterprises' dividend policies to shareholders and reduce China's comparative advantage given the abundance of low-wage labor (Cheung 2004, 2010). Moreover, rural-urban migrant workers tend to have very low pay, and they may accept jobs that pay less than the current minimum wage; thus, the minimum wage may exist in name only (Chan 2001).
} 
new regulations entered into force in March 2004, engendering frequent and substantial increases in the minimum wage in the years that followed. ${ }^{4}$

[Figure 2 about here]

Figure 2 shows the nominal and real minimum wage (monthly average) in China from 1995 to 2012 , as well as those of the corresponding provinces that raised the minimum wage standards for each year and the moving average over the same period. ${ }^{5}$ Between 1995 and 2003, the average nominal minimum wage increased steadily from $169 \mathrm{RMB}$ to $301 \mathrm{RMB}$, amounting to $78 \%$ growth over 9 years. However, since China promulgated the new minimum wage regulations in 2004, the nominal minimum wage has increased rapidly by more than $200 \%$, reaching $944 \mathrm{RMB}$ in $2012 .{ }^{6}$ The real minimum wage grew at a slower pace before 2004 and began to rise thereafter. Furthermore, as shown by the moving average curve in Figure 2, there is an apparent rise in the number of provinces that raised the minimum wage standards in 2004, indicating that minimum wage adjustments have become more frequent since 2004.

Although the literature widely documents numerous aspects of the minimum wage and its role in the labor market, there is no consensus regarding whether the minimum wage can reduce inequality (Neumark and Wascher 2008). Moreover, research on the effect of the minimum wage on inequality in developing countries is scant. Accordingly, this study examines whether increasing the minimum wage contributes to or counteracts increasing inequality. China provides a particularly interesting context for such a study since China has experienced both rising inequality and a rising minimum wage (nominal and real), whereas countries such as the

\footnotetext{
${ }^{4}$ According to our calculation, the average growth rate of the minimum wage is 10 to $20 \%$ per year throughout the country since 2004 .

${ }^{5}$ There is no national minimum wage in China; the minimum wage standards are determined at the provincial level. We discuss how we calculate the mean nominal and real minimum wage for each year in Section 4.1.

${ }^{6}$ The growth rates of the average nominal wage are $155 \%$ and $194 \%$ for the periods $1995-2003$ and 2004-2012, respectively (National Bureau of Statistics of China 2013).
} 
U.S. (Lee 1999) and Mexico (Bosch and Manacorda 2010) have experienced rising wage inequality with a declining minimum wage (real).

Using OLS and IV panel regressions at the aggregated city level, we first examine the effect of minimum wage changes on the earnings gaps at the bottom and upper end of the earnings distribution as well as the extent of such an effect. Our analysis shows that minimum wage increases significantly help reduce earnings gaps, particularly at the bottom end of the distribution. Next, to measure the contribution of minimum wage changes to the change in earnings inequality, we construct a counterfactual scenario to capture how China's earnings distribution would have evolved without the rise in the minimum wage. The difference between the observed and the counterfactual scenario is the real effect of the minimum wage. Indeed, we find that the contribution of minimum wage changes in reducing inequality is substantial, particularly at the bottom end of the earnings distribution. That is, had it not been for the increase in the minimum wage, the earnings gap at the bottom end of the earnings distribution would have been larger. ${ }^{7}$

The remainder of this study is organized as follows. We briefly review the literature in Section 2 and provide a review of the development of the minimum wage in China in Section 3. Section 4 provides details regarding the data and research design. In Section 5, we present and discuss the empirical results. Section 6 presents the conclusions.

\section{Literature on the Distributional Effect of the Minimum Wage}

Most evidence on the distributional effect of the minimum wage comes from the U.S. In early studies using simulation methods, Johnson and Browning (1983) and Burkhauser and Finegan (1989) show that a moderate reduction of the minimum wage could reduce income

\footnotetext{
${ }^{7}$ It is important to note that, like many studies do, our analysis assumes that minimum wage increases do not have an impact on employment or hours worked. Therefore, our results should be interpreted cautiously that the estimates could overstate the effect of minimum wage on reducing inequality.
} 
inequality. Since the 1990s, studies have commonly used regression methods. Neumark et al. (2005) apply a nonparametric method to estimate the minimum wage effect on income inequality, analyze several inequality measures (e.g., Gini coefficient, coefficient of variation, standard deviation, and Atkinson index) and find that a rise in the minimum wage can increase inequality. However, using data from 1979 to 1991 at the state level, Lee (1999) finds that the falling real minimum wage can explain from 70 to $100 \%$ of the growth in wage inequality in the lower tail of the female wage distribution and argues that declining the minimum wage accounts for a substantial part of the growth in inequality in the U.S. from 1979 to 1991. Autor et al. (2016) find that the minimum wage reduces wage inequality in the lower tail of the wage distribution (the 50/10 wage ratio), but the effects are typically less than half as large as those reported in Lee (1999) and are almost negligible for males. Taken together, most findings from the U.S. show that if the target group for the study of distributional effects is at the bottom end of the income/wage distribution, the minimum wage can help reduce inequality.

Evidence outside the U.S. is also limited, focusing primarily on Central and South American countries. The World Bank (2006) finds that the distributional effects of the minimum wage are ambiguous in Central and Southern America. Both positive and negative effects are found; however, the results show that the minimum wage has no effect on poverty and that the effect on inequality varies from country to country. Neumark et al. (2006) use a before-and-after method to study whether the minimum wage can help improve income inequality in Brazil and find that although the minimum wage has a positive effect on the income distribution at the 20th percentile, there is no effect at the 10th and 30th percentiles. Moreover, when a lagged minimum wage is added, the results show a significant negative effect. They also find that the results are not robust in different model specifications, and they ultimately conclude that the 
evidence from Brazil shows that the minimum wage does not reduce inequality. Gindling and Terrell (2007) use industry-level data from 2001 to 2004 in Honduras to study the effect of the minimum wage on the income distribution and find that the minimum wage has an effect in reducing inequality. Bosch and Manacorda (2010) study the effect of the minimum wage on earnings inequality in Mexico from the late 1980s to the early 2000s. They find that the Mexican minimum wage can explain a large part of earnings inequality in Mexico, and they show that at the bottom end of the earnings distribution, most of the growing inequality can be attributed to the rapid decline in the real value of the minimum wage.

Research on the effect of the minimum wage on inequality in China is limited. In the first empirical study, Wen (2007) uses pooled cross-sectional data from 2004 to 2006 at the provincial level to estimate the effect of the minimum wage on the employment and income distribution of rural migrant workers. He finds that the minimum wage has a positive effect on the employment and income distribution of rural migrants over the period of analysis. Wang (2011) discusses the effect of the minimum wage on patterns in the income distribution and economic development, and he argues that the minimum wage could have possibly reduced the income gap in China. Using the time-series data from Chongqing City for the period between 1997 and 2010, Chen (2012) finds that increasing the minimum wage could help mitigate the growing income gap between urban and rural areas.

Wang (2013) uses a simulation method and shows that increases in the minimum wage can reduce earnings inequality and that the effect of minimum wage policy increases with the strength of its enforcement. Jia (2013) uses microdata sets from three different surveys conducted between 1995 and 2008 to study the effect of the minimum wage on wage inequality, and he finds that increasing the effective minimum wage can help reduce wage differentials in 
the lower tail of the wage distribution. In the only study offer a different view of the minimum wage effect, Quan and Li (2011) test the growing income gap between urban and rural regions in Shanghai and show that the distributional effect of the minimum wage is limited.

In sum, almost all the limited studies on the minimum wage effect from China use aggregated data (published statistics), such as cross-sectional or time-series data. In contrast, information on the minimum wage (all at the provincial level) for calculating the mean minimum wage is insufficient. More important, the representativeness of the sample in previous studies is questionable. This study aims to address these concerns and to fill this research gap by providing a better data set, richer models and more complex estimation methods.

\section{The Minimum Wage Policy in China}

Prior to 1994, China had no minimum wage law. In 1984, the country simply acknowledged the 1928 "Minimum Wage Treaty" of the International Labour Organization (Su 1993). Because of sluggish wage growth and high inflation in the late 1980s, Zhuhai of Guangdong Province implemented the first local minimum wage regulations in 1989, and similar regulations followed in Shenzhen, Guangzhou, and Jiangmen in the same year. It was not until the eruption of private enterprises in 1992, when labor disputes became frequent, that the Chinese Central Government began to consider minimum wage legislation (Yang 2006). In 1993, China issued the first national minimum wage regulations, and in July 1994, these regulations were written into China's new version of the Labor Law.

The 1994 legislation required that all employers pay wages no less than the local minimum wage to employees. Further, all provincial, autonomous-region, and municipal governments were required to set the minimum wage according to five principles and report them to the State

Council of the Central Government. Specifically, the five principles indicated that the setting 
and adjustment of the local minimum wage should synthetically consider the lowest living expenses of workers, the average number of dependents workers support, local average wages, the level of labor productivity, the level of local employment, and the level of economic development among regions. These conditions provided considerable flexibility for provinces in setting minimum wage standards, with the economic development principle giving them the flexibility to limit the minimum wage to attract foreign investment (Wang and Gunderson 2011; Frost 2002). By December 1994, 7 of 31 provinces had set their own minimum wage, and by the end of 1995, that number had increased to 24 .

In the early 2000s, the slowly increasing minimum wage, along with growing concerns for uncovered/disadvantaged workers, began to increase the government's focus on new minimum wage regulations. In December 2003, the Ministry of Labor and Social Security passed "The Minimum Wage Regulations" and promulgated the new law in January 2004. Regarding its main features, this law extends coverage to employees in state-owned and private enterprises, self-employed businesses, and private nonenterprise units. In particular, the new law establishes two types of minimum wages: a monthly minimum wage applied to full-time workers and an hourly minimum wage applied to non-full-time employees. Moreover, the minimum wage standards are set and adjusted jointly by the local government, trade union, and enterprise confederation of each province. A draft for the minimum wage standards are submitted to the Ministry of Labor and Social Security for review, and the Ministry then asks for opinions from the All-China Federation of Trade Unions and the China Enterprise Confederation. The Ministry of Labor and Social Security can request a revision within 14 days of receiving the proposed draft. If no revision is brought up after the 14-day period, the proposed new minimum wage scheme is considered to be passed. 
In addition, the new regulation requires that local governments renew their minimum wage standards at least once every two years, and penalties for violations increased from $20 \%$ to $100 \%$ of the owed wage to $100 \%$ to $500 \%$ of the owed wage. ${ }^{8}$ Moreover, employers cannot include subsidies such as overtime pay or canteen and traveling supplements as part of employees' wage when calculating the minimum wage. The new regulations were entered into force on March 1 , 2004, and they have led to substantial increases in the minimum wage across China.

\section{Data and Research Design}

Although there is considerable interest in studying the effect of the minimum wage on inequality, research on this topic has been hampered by difficulties in collecting data. First, because provinces, municipalities, and autonomous regions in China have considerable flexibility in setting their minimum wage according to local conditions, at least 3 or 4 levels of minimum wage standards are often applicable to various cities in most provinces. ${ }^{9}$ Each city is responsible for documenting its own minimum wage standards; hence, city-level minimum wage data containing relevant information on the dates and extent of minimum wage increases are not readily available. ${ }^{10}$ Second, in China, it is difficult to obtain microdata that can reasonably be considered representative of the population and that may be influenced by minimum wage

\footnotetext{
${ }^{8}$ The increase in penalties for violations has significantly affected compliance. According to our calculation using 2002-2009 data, throughout the country, the share of workers who earn less than the minimum wage continuously declined, decreasing from 7.28 to $5.62 \%$ in the pre- and post-2004 periods (2002-2003, 2004-2009), respectively. In particular, the number decreased from 8.08 to $5.33 \%$ in the Eastern region between the same periods, whereas the number decreased from 6.19 to $5.46 \%$ in the Central region.

${ }^{9}$ For expositional convenience, we refer to "provinces, municipalities, and autonomous regions" as provinces.

${ }^{10}$ The implementation date of a new minimum wage standard of a city can also differ across geographically contiguous neighbors within the same province. For example, Liaoning Province has the most complicated minimum wage scheme, in which 14 jurisdictions may enact their own standards on different dates. For instance, in 2007, the cities of Shenyang, Benxi, Dandong, and Panjin did not increase their minimum wage. In contrast, on December 20, the cities of Dalian and Anshan increased their minimum wage from 600 RMB to $700 \mathrm{RMB}$, the cities of Jinzhou and Liaoyang increased their minimum wage from 480 RMB to $580 \mathrm{RMB}$, and the city of Chaoyang increased its minimum wage from 350 RMB to 530 RMB. Furthermore, the cities of Fushun and Huludao increased their minimum wage from $400 \mathrm{RMB}$ to $480 \mathrm{RMB}$ on January 1, whereas the city of Yingkou increased its minimum wage from 380 RMB to 480 RMB, the city of Fuxin increased its minimum wage from 350 RMB to 420 RMB, and the city of Tieling increased its minimum wage from $380 \mathrm{RMB}$ to $420 \mathrm{RMB}$ the following year.
} 
increases. Furthermore, some provinces, such as Beijing and Shanghai, do not include social security payments and housing provident funds as part of wages when calculating the minimum wage, rendering their "official" minimum wage higher than the real minimum wage. ${ }^{11}$ The data and research design were chosen to estimate the effect of the minimum wage on earnings inequality and to attempt to address some of the aforementioned challenges in research on the effect of the minimum wage on inequality. Hence, our study uses two data sources: 1. the annual Urban Household Survey (UHS) collected by NBS of China from 2002 to 2009 (more details in Section 4.1). 2. minimum wage data collected by authors at the city level (4-digit area code) between 1994 and 2012. ${ }^{12}$

\subsection{Data}

The UHS is a continuous, large-scale, socio-economic survey conducted by the NBS to study the conditions and standard of living of urban households, which include agricultural residents, nonagricultural residents, nonresidents who have lived in a city for at least six months and some migrant households with local residency. By using sampling techniques and daily accounting methods, the survey collects data from households in different cities and counties in all 31 provinces in Mainland China for each quarter. In late December, survey teams from all provinces are required to verify and then upload the aggregated annual data to the Division of City Socio-economic Survey of the NBS through Intranet by January 10 of the following year. The UHS data contain information on households, such as income, earnings, and consumption

\footnotetext{
${ }^{11}$ In other words, the difference between accounting for and not accounting for this issue can be substantial. For instance, the mean monthly minimum wage was 651 RMB and 767 RMB in Beijing and Shanghai in 2004-2009; however, the average expenses of both social security payments and housing provident funds in Beijing and Shanghai were as high as $376 \mathrm{RMB}$ and $452 \mathrm{RMB}$ over the same period, amounting to $58 \%$ and $59 \%$ of the nominal minimum wage, respectively. We discuss how we address this issue in the Data section.

${ }^{12}$ Because such detailed minimum wage data by city are not readily available to the public, our team at Beijing Normal University made an effort to collect the data ourselves.
} 
expenditures; demographic characteristics; work and employment; housing; and other familyrelated matters.

[Figure 3 about here]

Figure 3 shows the 16-province sample for the analysis (represented by darker areas), which includes two major municipalities, Beijing and Shanghai; four economically important provinces in the Eastern region (more prosperous), Guangdong, Jiangsu, Shandong, and Liaoning; five provinces in the Central region (developing), Henan, Anhui, Hubei, Jiangxi, and Shanxi; and four provinces in the Western region (less developed), Chongqing, Gansu, Sichuan, and Yunnan. Overall, our 16-province sample contains $65 \%$ of the total population in China and covers $60 \%$ of the cities in the country (National Bureau of Statistics of China 2010). ${ }^{13}$

Our primary objective is to thoroughly and accurately acquire relevant information on the minimum wage for each city. In China, provinces have considerable flexibility in setting their minimum wage standards according to local economic conditions; thus, there are several levels of standards across cities within the same province. Moreover, the adjustment date of a city's new minimum wage standards can also differ from its geographically contiguous neighbors within the same province, rendering the estimation of minimum wage effects more challenging. To effectively address this issue, we collected our minimum wage data from every local government web site and carefully recorded the minimum wage information for every year from 1994 to 2012. As such, our data contain the monthly minimum wage for full-time employees, the hourly minimum wage for part-time employees, the effective dates of the minimum wage standards and the extent to which social security payments and/or housing provident funds were included as part of the minimum wage calculations. We then merge the minimum wage data

\footnotetext{
${ }^{13}$ Note that the UHS data are not publicly available. The NBS allows limited access to the microdata for up to 16 provinces under certain conditions for academic research. Nonetheless, the 16-province sample includes almost all economically important provinces in China.
} 
with the UHS data, a 16-province data set containing individual/household socio-economic information for the period 2002-2009.

\section{[Table 1 about here]}

In Table 1, we present a brief summary of the minimum wage data used in our main analysis for the period following the implementation of new minimum wage regulations (2004). Columns (1), (2), and (3) correspond to the mean of the monthly minimum wage, the standard deviation, and the number of counties for the three regions and the 16 provinces in 2004 , respectively. ${ }^{14}$ When calculating the mean minimum wage, we use a time-weighted method, as suggested in Rama (2001), to address the issue of different adjustment dates among cities in a province within a year. The mean minimum wage is adjusted for inflation and converted into 2005 RMB by using the urban resident CPI for comparison over time. In addition, to account for the differing living costs among provinces, we apply the PPP-adjusted deflator developed by Brandt and Holz (2006). ${ }^{15}$ The last row reports the mean of the minimum wage for all provinces, its standard deviation, and the total number of counties for each year.

Table 1 reveals several important patterns. First, the mean nominal minimum wage increased by $80 \%$ (from 310 RMB to 562 RMB) between 2004 and 2009 throughout China. ${ }^{16}$ Second, the Eastern region has the highest minimum wage during this period, with an average of 522 RMB per month, and the Western (436 RMB) and Central regions (424 RMB) follow. Surprisingly, the minimum wage shows a similar annual growth rate of $13 \%$ for the three regions. ${ }^{17}$ Third, the minimum wage was sometimes raised more than once in a year. For

\footnotetext{
${ }^{14}$ Note that there was no minimum wage increase in 2009 because of the global financial crisis.

${ }^{15}$ The updated version, which is extended to 2010, is available at http://ihome.ust.hk/ socholz/SpatialDeflators.html.

${ }^{16} \mathrm{In}$ fact, the average real minimum wage has also grown at a similar rate.

${ }^{17}$ The average annual growth rate of the minimum wage is $12.7 \%$ in the Eastern region, $13.2 \%$ in the Central region, and $12.5 \%$ in the Western region over the period 2004-2009.
} 
example, Beijing increased its minimum wage in January and July of 2004, and Jiangsu raised its minimum wage in April and July of 2008.

We restrict the analysis to salaried workers between the ages of 16 and 59 who are employed in the civilian labor force, report positive annual earnings, are not self-employed, and are not enrolled in school. To reduce the effect from outliers, we winsorize the top two percentiles of the earnings distribution in each city-year group by assigning the value of the 97th percentile to the 98th and 99th percentiles. ${ }^{18}$ Sampling weights are used in all calculations.

[Table 2 about here]

In Table 2, we provide summary statistics for the workers in our sample for the period 20042009. The total number of observations is 289,009 . The mean age is approximately 41 years, and men compose $55 \%$ of the sample. Furthermore, the workers earn 237,716 RMB on average annually, the average number of years of schooling is 12.87 , and approximately $97 \%$ of the workers are of Han ethnicity. Regarding marital status, $88 \%$ of the workers are married with a spouse present. Because of the nature of the UHS, not surprisingly, $97 \%$ of the workers have local hukou (legal household registration in a city), and the average length of residence in a city is 31 years. Finally, the average work experience is approximately 22 years.

[Table 3 about here]

In Table 3, we summarize the characteristics of the minimum wage standards in China. The first row of Table 3 shows that approximately $6.81 \%$ of all workers earn less than the minimum wage and that $1.88 \%$ earn the minimum wage, indicating that $8.69 \%$ of Chinese employees are minimum wage workers during the period 2004-2009. ${ }^{19}$ Among those who earned the minimum

\footnotetext{
${ }^{18}$ Alternatively, we also drop the top 99th percentile and the bottom 1st percentile, and the results are not affected.

${ }^{19}$ Our number is close to Ye et al. (2015) who use a matched Chinese firm-employee data in 2009 that that compliance rates are as high as $96.5 \%$ for full time workers. Nevertheless, bindingness of the minimum wage can affect our analysis. Due to data limitation, we are not able to investigate this issue so our results should be
} 
wage or less than the minimum wage, $63.81 \%$ and $62.38 \%$ are females, respectively. Furthermore, the minimum-to-average-wage ratio of workers receiving less than the minimum wage is 2.35 , indicating that these disadvantaged workers earn a wage that is only approximately one-quarter of the official standard. Regarding regional differences, in the Eastern and Central regions, approximately $92 \%$ of the workers earn a wage above the minimum wage, whereas the corresponding figure for the Western region is $89 \%$.

Regarding the different age cohorts, Table 3 shows that teenagers (age 16-19) are very likely to be minimum wage workers, as approximately $47 \%$ of teenagers in our sample are minimum wage workers. The percentage of minimum wage workers decreases substantially as workers' age increases. A similar decreasing pattern is observed with respect to skill, as measured by educational attainment. Regarding the characteristics of workers by occupation and industry, Table 3 shows that $19 \%$ of workers in clerical and related occupations and commercial service occupations earn the minimum wage. The housekeeping industry has the largest share of minimum wage workers, with approximately $20 \%$ of housekeepers earning the minimum wage or less. In both the wholesale and retail sector and the hotel and restaurant sector, approximately $16 \%$ of workers earn the minimum wage or less.

\subsection{Research Design}

Our objective is to assess the effect of the minimum wage on the earnings distribution in China. As noted in Section 2, nearly all existing studies on the minimum wage in China use pooled time-series/cross-section data at the provincial level and report mixed results, implying that a "consensus" regarding distributional effects of the minimum wage remains to be established. Thus, our study attempts to reconcile existing findings by using detailed/complete

interpreted with caution. Several studies have attempted to deal with the issues of enforcement and compliance such as Gindling et al. (2015) for Costa Rica, Bhorat et al. (2012) for South Africa, Ronconi (2010) for Argentina, and Ye et al. (2015) for China. 
minimum wage data, which allow us to employ a panel structure analysis of minimum wage effects, to exploit the greater variation in the relative minimum wage at the city level and to avoid the measurement error caused by using a uniform provincial minimum wage. Moreover, unlike previous studies that use aggregate published statistics, our study uses household survey microdata, which allow us to calculate the dependent variable - earnings differentials - at the city level. Thus, the dependent variable contains more variation and information on local conditions. Ideally, this feature should facilitate more reliable estimates of the distributional effects of the minimum wage in China. ${ }^{20}$

Following Lee (1999) and Autor et al. (2016), we parameterize the minimum wage effect as a quadratic function of the difference between the log minimum wage and the $p$-th percentile of the actual log earnings distribution by expressing the $q$ to $p$ percentile differential $w_{c t}^{q}-w_{c t}^{p}$ as a function of the latent wage differential plus a minimum wage effect. That is, our estimation equation is

$$
w_{c t}^{q}-w_{c t}^{p}=\beta_{1}^{q}\left(M W_{c t}-w_{c t}^{p}\right)+\beta_{2}^{q}\left(M W_{c t}-w_{c t}^{p}\right)^{2}+X_{c t}^{\prime} \gamma^{q}+\alpha_{c}^{q}+\alpha_{t}^{q}+u_{c q t},
$$

where $M W_{c t}-w_{c t}^{p}$ is the "effective" minimum wage variable of city $c$ in year $t$, denoting the minimum wage relative to some level of local earnings that is unaffected by the minimum wage and that proxies for local living standards. We include a quadratic term " $\left(M W_{c t}-w_{c t}^{p}\right)^{2}$ ” in the equation to capture the property that $w_{c t}^{q}-w_{c t}^{p}$ exhibits "flatten[ing] to the left", as proposed by Lee (1999) and shown in Figure 4; for example, the quadratic term for 2008 is statistically significant at the $5 \%$ level. In estimating Eq.(1), $w_{c t}^{p}$ is defined as the median wage. Further, $X$ is a set of control variables used to capture aggregate business cycle effects; $\alpha_{t}^{q}$ is a set of year

\footnotetext{
${ }^{20}$ As stated in Section 1, our analysis assumes minimum wages have no effects on employment or hours. We discuss how this assumption affects the interpretation of our results in the last paragraph of Section 5.1.
} 
fixed effects; and $\alpha_{c}^{q}$ is a set of city fixed effects. The disturbance term $u$ is assumed to be independent of city and year effects. $^{21}$

Lee (1999) assumes the errors are orthogonal to the independent variables (the effective minimum wage and its square) in his estimation. However, Autor et al. (2016) point out the problem with the OLS estimation of Eq. (1) is that potential measurement errors will lead to upward biased estimates of the effect of the minimum wage on inequality in both the lower and upper tail of the earnings/wage distribution. Hence, Autor et al. (2016) follow the approach in Durbin (1954) by applying IVs to address the bias caused by such measurement error problem. Likewise, Bosch and Manacorda (2010) apply IV approach to address this issue in their study on Mexico. Since we use Lee's methodology, we need instruments to deal with the problem of measurement error. In the 2 SLS regressions, we instrument the observed effective minimum wage and its square by using three instruments as in Autor et al. (2016): 1) the log of the real minimum wage, 2) the square of the log of the real minimum wage, and 3) the interaction between the $\log$ minimum wage and the average log median real wage for the city over the sample period. In such specification, identification for the effective minimum wage $\left(M W_{c t}-w_{c t}^{p}\right)$ in Eq.(1) fully comes from the variation of 1) the log of the real minimum wage and identification for the quadratic term $\left(M W_{c t}-w_{c t}^{p}\right)^{2}$ comes from 2) the square of the log of the real minimum wage and 3) the interaction term.

\subsection{Counterfactual Estimates of Changes in Earnings Inequality}

To measure the contribution of the increase in the effective minimum wage to the observed rise in China's earnings inequality over the period 2004-2009, we compare actual and

\footnotetext{
${ }^{21} \mathrm{We}$ also include several control variables in the equation to try to reduce the concern of endogeneity. First, the city's GDP per capita and CPI (city level) capture aggregate business cycle effects and control for the global financial crisis. Second, the city's level of foreign direct investment (FDI) is used to control for provinces that may restrain the minimum wage to attract foreign investors (Frost 2002).
} 
counterfactual estimates of changes in earnings differentials. Conceptually, we calculate counterfactual estimates of changes in latent earnings differentials without the rise in the minimum wage - that is, the change in earnings gap that would have been observed had the minimum wage been held at a constant, real benchmark.

Lee (1999) and Autor et al. (2016) propose the following simple procedure to estimate changes in latent earnings differentials. For each observation in the data set, we calculate its rank in its respective city-year earnings distribution. Then, to simulate the earnings of the $q$ th percentile worker in city $c$ in $t_{1}$ (such as 2009) with the minimum wage at its $t_{0}$ (such as 2004) relative level, we adjust each worker's actual log earnings by the quantity:

$$
\Delta w_{c t}^{q}=\hat{\bar{\beta}}_{1}^{q}\left(\widetilde{M W}_{c, t_{0}}-\widetilde{M W}_{c, t_{1}}\right)+\hat{\bar{\beta}}_{2}^{q}\left(\widetilde{M W}_{c, t_{0}}^{2}-\widetilde{M W}_{c, t_{1}}^{2}\right)
$$

where $\widetilde{M W}_{c, t_{1}}$ is the observed end-of-period effective minimum wage in city $\mathrm{c}$ in $t_{1}, \widetilde{M W}_{c, t_{0}}$ is the corresponding beginning-of-period effective minimum in $t_{0}, \hat{\bar{\beta}}_{1}^{q}$ and $\hat{\bar{\beta}}_{2}^{q}$ are estimated coefficients from Appendix Tables 1 and 2. Take $t_{0}=2004$ and $t_{1}=2009$ example, adding $\Delta w_{c t}^{q}$ to each observed earnings in 2009 would adjust the 2009 earnings distribution to its counterfactual under the realized effective minimum wage in 2004. Next, we pool these adjusted earnings distribution to get a counterfactual national earnings distribution, and then compare changes in earnings inequality between the observed earnings distribution and the simulated 
distribution obtained from the above method. ${ }^{22}$ Finally, standard errors are calculated by bootstrapping the estimates within the city-year panel. ${ }^{23}$

\section{Empirical Results and Discussion}

\subsection{Minimum Wage Effects on Earnings Differentials}

We first present the estimation results of minimum wage effects on earnings differentials in Table 4. In each column, we estimate Eq.(1) by using a fixed-effects model with four different specifications. All regressions are weighted by the size of the city's population, and standard errors (in parentheses) are clustered at the city level. Entries in the tables refer to the estimated first derivative (marginal effect) of each dependent variable with respect to the effective minimum wage evaluated at the population-weighted average across cities and years. ${ }^{24}$ In addition to OLS, we use 2SLS regression to address potential endogeneity issues as suggested in Autor et al. (2016). To check the validity of our instruments, we report results for the weak identification test and overidentification test (Hansen $\mathrm{J}$ statistics) in Appendix Tables 1 to 4. Except specification (1) for the p75-p90 and p90-p50 earnings differentials in Appendix Tables 3 and 4, which reject the exogeneity of the instruments, all other test results show that our instruments are valid. ${ }^{25}$

[Table 4 about here]

${ }^{22} \widetilde{M W}$ is calculated by correcting the estimation for changes in the minimum wage and changes in the city's median earnings, while Lee (1999) and Autor et al. (2016) use national and state median wages when calculating $\widetilde{M W}$.

${ }^{23}$ As in Autor et al. (2016), we start by drawing cities with replacement in our sample and then estimate Eq.(1) and apply the coefficients to compute the counterfactual in Eq.(2). We report the standard deviation using 200 replications in Table 5.

${ }^{24}$ That is, each entry mean is $\beta_{1}^{q}+2 \beta_{2}^{q}\left(M W-w^{p}\right)$, where variables without the $c t$ subscript refer to the sample mean values over all cities and all periods.

${ }^{25}$ For all 2 SLS models, the weak identification test shows that the instruments are highly significant and able to pass standard diagnostic tests for weak instruments, as suggested in Stock et al. (2002). 
We report the OLS and 2SLS results in terms of the marginal effects of four specifications for each percentile gap. Each entry refers to a separate regression, where each row refers to the differential between the 10th, 25th, 75th, and 90th percentiles of the earnings distribution and the median. The first column of Table 4 reports the estimates with cluster-robust standard errors at the city level presented in parentheses for the specification using fixed year and city effects. In the second column, we report the estimates of the specification with fixed year and city effects and the interaction of the province and year dummies. This specification allows us to abstract from the differential changes in the minimum wage and latent wages across cities. The estimation of the third column further contains city trends, whereas in the fourth column, we additionally include city covariates to control for the local economic conditions and business cycle effects.

The significance of our results is compelling: Overall, we find that the minimum wage can reduce the earnings differentials at the bottom end of the earnings distribution (i.e., p50-p10 and p50-p25); in contrast, as a placebo test, we do not find a statistically significant effect at the upper end of the earnings distribution (e.g., p75-p50 and p90-p50). For example, the OLS estimates of -.118 and -.094 in column (1) show that a $10 \%$ increase in the effective minimum wage leads to statistically significant $1.18 \%$ and $.94 \%$ reductions in the p50-p10 and p50-p25 earnings differentials, and the corresponding reductions according to the marginal effects of the 2SLS results are $2.77 \%$ and $1.63 \%$, which are also statistically significant. As expected, the point estimates tend to be smaller for the p50-p25 earnings differential than for the p50-p10 earnings differential, implying some spillover, but the effect is attenuated as we move up the earnings distribution ladder. ${ }^{26}$ Note that the OLS and 2SLS results at the upper end (p75-p50

\footnotetext{
${ }^{26}$ The spillover effects of the minimum wage are quite evident from our results. However, Autor et al. (2016) provide a mundane but plausible explanation for their findings of spillover effects using US data is measurement
} 
and p90-p50) are not statistically significant, suggesting the minimum wage does not have an effect on earnings above the median.

In column (2) of Table 4, we additionally control for the interaction of the year dummies with the province dummies. By including province-year interaction fixed effects, we control for city-specific factors that have been shown to be important predictors of changes in the earnings structure. These regressions effectively identify the effect of the minimum wage based on its differential variation across cities. Compared with the results in column (1), the 2SLS results in column (2) show weaker effects of the minimum wage on the earnings distribution by reducing the earnings gaps at the bottom end of the distribution.

Column (3) of Table 4 additionally controls for city-specific linear time trends. As shown, the marginal effects decrease in absolute value for the p50-p10 and p50-p25 earnings differentials in the 2SLS estimates. The marginal effects are statistically significant up to the median and are not significant afterward, implying pronounced spillover effects of the minimum wage that propagate to higher percentiles of the earnings distribution at the bottom but not the upper end of the earnings distribution. For example, the 2SLS result in column (3) for the period 2004-2009 suggest that a $10 \%$ increase in the effective minimum wage reduces the p50-p10 earnings differential by almost .206 log points and the p50-p25 earnings differential by $146 \log$ points.

Potential concerns regarding the results in the previous columns are that the correlation between earnings inequality and the minimum wage might be contaminated by the opening of

error. Since we are using household survey data and survey data on sensitive questions such as earnings often have considerable measurement error, it is possible that the spillover effects we find may be due to measurement error. On the other hand, Jia and Zhang (2013) find spillover effects of minimum wages in China using a longitudinal data at individual level from China Health and Nutrition Survey. Their results indicate that spillover effects of the minimum wage increase can reach to 1.50 and 1.25 times of minimum wages on male and female wage distribution, respectively. Although we cannot rule out the possibility of measurement error, our use of IV regression can substantially reduce this concern as shown in Autor et al. (2016) 
the Chinese economy after China became an official member of the WTO in December of 2001 and that soaring FDI might have contributed to shaping the trends in earnings inequality, as others have claimed. To address these possible issues, we additionally control for factors that might be correlated with the trend in the effective minimum wage. The marginal effects that include these additional controls are presented in column (4) of Table 4, and they are smaller than those in columns (1), (2), and (3). In short, we find that minimum wage changes have reduced earnings inequality in China by essentially decreasing earnings gaps at the bottom end of the earnings distribution. ${ }^{27}$

Note that our results are based on the assumption that minimum wages have effects on employment or hours. However, recent studies that use firm level or household surveys to exam the employment effect of minimum wages in China have found either negative or no effects (Huang, Loungani, and Wang 2014; Fang and Lin 2015; Mayneris, Poncet, and Zhang 2014). In particular, Ye, Gindling, and Li (2015) use a 2009 matched firm-employee data which contains detailed wage information (basic monthly wages, bonus, supplements, and hours) and find evidence that Chinese firms adjust to the higher minimum wage by increasing hours worked of those low-skilled workers in the most labor-intensive firms. If we were to consider these findings that employment and hours go down in response to a minimum wage change, our estimates could overstate the effect of minimum wages on reducing earnings inequality in China and should be interpreted with caution.

\footnotetext{
${ }^{27}$ Note that if the endogeneity problem we try to instrument for mainly comes from measurement error, we would expect the 2SLS estimates in Table 4 to be smaller (in absolute value) than the OLS estimates. As expected, the upper end of the earnings distribution (p75-p50 and p90-p50) shows that the 2SLS estimates are smaller than the OLS estimates (except specification 1). However, for the lower end (p50-p10 and p50-p25) shows the opposite. There can be two possible reasons. First, it could be possible that the measurement error problem is not the major endogeneity issue (not as severe as we expect in the lower end of the earnings distribution in the data). Second, our instruments marginally pass the Stock \& Yogo's weak instrument test, signaling we might have weak instrument issues. Due to lack of data, we are not able to pursue further. Although we cannot rule out these concerns, our conclusions do not change and should be interpreted with caution.
} 


\subsection{Results of Counterfactual Estimates of Changes in Earnings Inequality}

Table 5 presents the results of the counterfactual estimates of changes in the p50-p10 and p50-p25 earnings differentials. The calculations are done at the city level by using the estimated coefficients from Appendix Tables 1 and 2 and the method illustrated in Section 4.3. The third column reports the earnings differentials in log points for 2004 and 2009. The fourth column presents the observed actual change, which equals the difference in the log gaps of 2004 and 2009 times 100, whereas the fifth and the sixth columns provide the counterfactual estimates of the latent change (100 times the log change) based on the OLS and 2SLS results from the four model specifications.

\section{[Table 5 about here]}

Because the minimum wage policy particularly aims to help low-earning workers, we are interested in how the minimum wage affects inequality at the bottom half of the earnings distribution. Take the p50-p10 earnings differential as an example: The actual log earnings gap is .892 in 2004 and .922 in 2009 . Hence, the actual change is -.0296 log points between the two years, indicating that the earnings inequality deteriorates. Had there been no minimum wage increase between 2004 and 2009, what would the p50-p10 earnings gap be in 2009? We answer this counterfactual question by reporting the latent changes: The numbers are larger for both the OLS and the 2SLS models and for all specifications. For example, the latent change in 2SLS specifications (1) and (4) is -.0495 and -.0360 log points, respectively, which indicates that the p50-p10 earnings gap in 2009 would have been 67 to $22 \%$ higher if the minimum wage had not increased. Note that the numbers are lower than those in Lee (1999) but close to those in Autor et al. (2016). The results for the p50-p25 earnings differential tell a similar story, i.e., that the 
inequality would have been higher if there were no minimum wage increase in China between 2004 and 2009.

\section{Conclusions}

We use a large set of panel data at the city level that contains relevant information on the minimum wage, combined with a longitudinal household survey of 16 representative provinces, to estimate the distributional effect of minimum wage changes in China over the period 20042009. Compared with previous studies using provincial-level data and reporting mixed results, our study shows that minimum wage changes significantly help reduce the earnings gap at the bottom end of the earnings distribution. In a placebo test, we do not find that minimum wage changes have an effect on the earnings gap at the upper end of the distribution.

To gauge the contribution of minimum wage increases to reducing earnings inequality, we calculate the counterfactual changes in earnings differentials and decompose the total change in China's earnings distribution. Indeed, we find that minimum wage changes substantially contribute to reducing the earnings gap at the bottom end of the distribution. Likewise, the results for the Gini coefficients and variance in our analysis suggest that the minimum wage helps reduce earnings inequality.

In sum, our findings are consistent with recent studies reporting that the minimum wage plays an essential role in earnings/wage inequality. Both the U.S. and Mexico have exhibited a declining minimum wage (both real and effective) and rising inequality, and empirical evidence shows that the declining minimum wage accounts for a substantial part of the growth in inequality in both countries over the past three decades (Autor et al. 2016; Bosch and Manacorda

2010; Lee 1999). In contrast, China has experienced a rapid increase in the minimum wage and rapidly increasing inequality in the past 10 years, which provides an opportunity to study the 
effect of the minimum wage on inequality in an environment that differs from that in prior research (e.g., U.S. and Mexico). Our finding that minimum wage increases have reduced inequality — by reducing earnings gaps particularly at the bottom end of the earnings distribution-has both regional relevance and general implications in the context of the minimum wage literature.

\section{References}

Addison, John T., and McKinley L. Blackburn. 1999. "Minimum Wages and Poverty." Industrial and Labor Relations Review 52 (3):393-409.

Autor, David H., Alan Manning, and Christopher L. Smith. 2016. "The Contribution of the Minimum Wage to U.S. Wage Inequality over Three Decades: A Reassessment." American Economic Journal: Applied Economics, 8(1), 58-99.

Bosch, Mariano, and Marco Manacorda. 2010. "Minimum Wages and Earnings Inequality in Urban Mexico." American Economic Journal: Applied Economics 2 (4):128-49.

Brandt, Loren, and Carsten A. Holz. 2006. "Spatial Price Differences in China: Estimates and Implications." Economic Development and Cultural Change 55 (1):43-86.

Burkhauser, Richard V., and T. Aldrich Finegan. 1989. "The Minimum Wage and the Poor: The End of a Relationship." Journal of Policy Analysis and Management 8 (1):53-71.

Card, David, and Alan B. Krueger. 1995. Myth and Measurement: The New Economics of the Minimum Wage. Princeton: Princeton University Press.

Chan, Anita. 2001. China's Workers under Assault: The Exploitation of Labor in a Globalizing Economy: ME Sharpe.

Chen, Jing. 2012. The Employment Effect and Income Distribution Effect from the Minimum Wage Standard: Evidence of Chongqing, Chongqing Normal University (in Chinese).

Chernozhukov, Victor, Iván Fernández-Val, and Blaise Melly. 2013. "Inference on Counterfactual Distributions." Econometrica 81 (6):2205-68.

Cheung, Steven N. S. 2004. Another Eye on Minimum Wages. In Southern Weekly. June 17 (in Chinese). Chinese). .2010. The Lethality of Minimum Wages. In Economic Information Daily. February 24 (in Cooke, Fang Lee. 2005. HRM, Work and Employment in China: Routledge.

DiNardo, John, Nicole M. Fortin, and Thomas Lemieux. 1996. "Labor Market Institutions and the Distribution of Wages, 1973-1992: A Semiparametric Approach." Econometrica 64 (5):1001-44. 
Durbin, J., 1954. Errors in Variables. Revue de l'Institut International de Statistique / Review of the International Statistical Institute 22, 23-32.

Frost, Stephen. 2002. Labour Standards in China: The Business and Investment Challenge. In Association for Sustainable and Responsible Investment in Asia.

Gindling, T. H., and Katherine Terrell. 2007. "The Effects of Multiple Minimum Wages Throughout the Labor Market: The Case of Costa Rica." Labour Economics 14 (3):485-511.

Jia, Peng. 2013. Minimum Wage Effects on Employment and Income Distribution, Jilin University (in Chinese).

Jia, Peng., Shiwei. Zhang, 2013. Spillover Effects of Minimum Wages Increase. Statistical Research 30, 37-41 (in Chinese).

Johnson, William R., and Edgar K. Browning. 1983. The Distributional and Efficiency Effects of Increasing the Minimum Wage: A Simulation. In American Economic Review.

Lee, David S. 1999. "Wage Inequality in the United States During the 1980s: Rising Dispersion or Falling Minimum Wage?" The Quarterly Journal of Economics 114 (3):977-1023.

Li, Shi, and Chuliang Luo. 2011. "How Unequal Is China?" Economic Research Journal 4:68-78 (in Chinese).

Li, Shi, and Renwei Zhao. 1999. "Re-Examining the Income Distribution in China." Economic Research Journal 4 (in Chinese).

National Bureau of Statistics of China. 2010. The 6th China Population Census. . 2013. "China Labour Statistical Year Book."

Neumark, David, Wendy Cunningham, and Luca Siga. 2006. "The Effects of the Minimum Wage in Brazil on the Distribution of Family Incomes: 1996-2001." Journal of Development Economics 80 (1):136-59.

Neumark, David, Mark Schweitzer, and William Wascher. 2005. "The Effects of Minimum Wages on the Distribution of Family Incomes: A Nonparametric Analysis." Journal of Human Resources 40 (4):867-94.

Neumark, David, and William L. Wascher. 2008. Minimum Wages. Cambridge, Mass.: MIT Press.

Quan, Heng, and Ling Li. 2011. "The Income Distribution Effect of Minimum Wage in Shanghai: Evidence and Simulation." Shanghai Economic Research 4:96-109.

Stock, James H., Jonathan H. Wright, and Motohiro Yogo. 2002. "A Survey of Weak Instruments and Weak Identification in Generalized Method of Moments." Journal of Business \& Economic Statistics 20 (4):518-29.

Su, Hainan. 1993. "Research on the Legislation of Minimum Wage Law of China." Review of Economic Research Z1:26-36 (in Chinese).

Wang, Dihai. 2011. "On the Minimum Wage System of China: Probable Effects on Income Distribution and Economic Development." Zhejiang Social Sciences 2:11-17 (in Chinese). 
Wang, Dan. 2013. Minimum Wage Effects on Income Distribution, Jilin University (in Chinese).

Wang, Haigang. 2007. Income Distribution and Income Liquidity of Residents in China: Sun Yat-Sen University (in Chinese).

Wang, Jing, and Morley Gunderson. 2011. "Minimum Wage Impacts in China: Estimates from a Prespecified Research Design, 2000-2007." Contemporary Economic Policy 29 (3):392-406.

Wen, Qidong. 2007. Research on the Effect of Minimum Wages on Rural Migrants' Employment and Income Distribution, University of Electronic Science and Technology of China (in Chinese).

World Bank. 2006. Minimum Wages in Latin America and the Caribbean: The Impact on Employment, Inequality, and Poverty. Washington, D.C.: Office of the Chief Economist.

Yang, Tao. 2006. What Is the Social Background When China Implemented Its Minimum Wage Law? In People's Daily. 
Table 1 Minimum Wages Across Various Jurisdictions in China, 2004-2009

\begin{tabular}{|c|c|c|c|c|c|c|c|c|c|c|c|c|c|c|c|c|c|c|}
\hline \multirow{2}{*}{ Province } & \multicolumn{3}{|c|}{2004} & \multicolumn{3}{|c|}{2005} & \multicolumn{3}{|c|}{2006} & \multicolumn{3}{|c|}{2007} & \multicolumn{3}{|c|}{2008} & \multicolumn{3}{|c|}{2009} \\
\hline & MW & S.D. & Obs. & MW & S.D. & Obs. & MW & S.D. & Obs. & MW & S.D. & Obs. & MW & S.D. & Obs. & MW & S.D. & Obs. \\
\hline \multicolumn{19}{|l|}{ East } \\
\hline Beijing & 509.5 & .0 & 2 & 562.5 & .0 & 2 & 611.8 & .0 & 2 & 665.4 & .0 & 2 & 735.4 & .0 & 2 & 820.1 & .0 & 2 \\
\hline Shanghai & 590.3 & .0 & 2 & 662.5 & .0 & 2 & 712.1 & .0 & 2 & 757.7 & .0 & 2 & 894.0 & .0 & 2 & 984.2 & .0 & 2 \\
\hline Liaoning & 282.3 & 46.0 & 96 & 361.9 & 36.6 & 96 & 405.5 & 41.2 & 96 & 465.8 & 48.7 & 96 & 550.1 & 59.9 & 97 & 587.8 & 63.2 & 97 \\
\hline Shandong & 348.4 & 35.2 & 129 & 440.9 & 50.0 & 129 & 454.6 & 53.5 & 129 & 476.2 & 66.3 & 129 & 571.9 & 75.6 & 129 & 609.9 & 80.6 & 129 \\
\hline Jiangsu & 416.2 & 59.9 & 66 & 457.6 & 66.8 & 66 & 517.9 & 70.4 & 66 & 591.0 & 78.0 & 75 & 647.8 & 88.1 & 75 & 694.4 & 94.7 & 75 \\
\hline Guangdong & 361.2 & 59.9 & 104 & 442.1 & 80.6 & 104 & 475.0 & 84.9 & 104 & 516.6 & 88.5 & 104 & 574.3 & 88.2 & 104 & 636.1 & 98.2 & 104 \\
\hline All East & 349.1 & 68.5 & 339 & 426.7 & 72.1 & 399 & 460.6 & 76.0 & 399 & 507.4 & 86.5 & 408 & 583.6 & 87.6 & 409 & 629.7 & 95.7 & 409 \\
\hline \multicolumn{19}{|l|}{ Central } \\
\hline Heilongjiang & 282.0 & 28.1 & 30 & 287.8 & 28.7 & 30 & 384.0 & 45.7 & 30 & 418.0 & 53.6 & 30 & 456.0 & 58.6 & 30 & 486.3 & 62.5 & 30 \\
\hline Anhui & 304.6 & 11.7 & 86 & 330.7 & 17.1 & 86 & 350.1 & 19.1 & 86 & 400.7 & 27.1 & 86 & 420.4 & 29.2 & 86 & 448.3 & 31.2 & 86 \\
\hline Jiangxi & 246.7 & 6.6 & 99 & 317.7 & 8.9 & 100 & 328.9 & 9.4 & 100 & 427.5 & 15.2 & 100 & 460.3 & 21.8 & 100 & 490.9 & 23.3 & 100 \\
\hline Shanxi & 348.2 & 21.8 & 119 & 445.4 & 22.3 & 119 & 454.2 & 22.4 & 119 & 476.3 & 21.6 & 119 & 536.6 & 22.8 & 119 & 642.5 & 28.6 & 119 \\
\hline Hubei & 271.9 & 34.9 & 89 & 320.6 & 36.8 & 89 & 330.2 & 37.2 & 89 & 402.4 & 39.1 & 89 & 453.4 & 45.6 & 89 & 541.5 & 58.5 & 89 \\
\hline Henan & 251.5 & 15.5 & 127 & 278.5 & 17.0 & 127 & 345.0 & 27.9 & 127 & 371.1 & 25.7 & 127 & 477.2 & 42.5 & 127 & 509.0 & 45.3 & 127 \\
\hline All Central & 284.8 & 43.6 & 550 & 337.1 & 63.8 & 551 & 366.2 & 54.7 & 551 & 416.3 & 46.3 & 551 & 473.1 & 51.7 & 551 & 529.1 & 77.0 & 551 \\
\hline \multicolumn{19}{|l|}{ West } \\
\hline Gansu & 298.2 & 8.5 & 87 & 304.4 & 8.7 & 87 & 322.1 & 16.3 & 87 & 344.6 & 35.1 & 87 & 471.6 & 36.3 & 87 & 549.4 & 39.2 & 87 \\
\hline Chongqing & 334.7 & 21.7 & 42 & 365.7 & 24.6 & 42 & 409.0 & 30.1 & 42 & 477.8 & 39.8 & 42 & 554.8 & 44.5 & 42 & 591.7 & 47.4 & 42 \\
\hline Sichuan & 295.4 & 32.1 & 50 & 352.2 & 41.9 & 50 & 392.2 & 43.8 & 50 & 425.0 & 42.3 & 181 & 477.9 & 53.0 & 181 & 509.7 & 56.5 & 181 \\
\hline Yunnan & 297.5 & 18.0 & 138 & 365.2 & 23.4 & 138 & 403.6 & 23.4 & 138 & 427.0 & 22.8 & 138 & 527.2 & 31.5 & 138 & 562.3 & 33.6 & 138 \\
\hline All West & 302.3 & 23.3 & 317 & 346.5 & 36.1 & 317 & 380.1 & 45.0 & 317 & 414.9 & 51.8 & 448 & 499.1 & 52.3 & 448 & 541.3 & 54.1 & 448 \\
\hline All Provinces & 309.5 & 56.7 & 1266 & 367.7 & 73.1 & 1267 & 399.4 & 73.3 & 1267 & 442.3 & 74.8 & 1407 & 513.5 & 79.2 & 1408 & 562.2 & 88.3 & 1408 \\
\hline
\end{tabular}

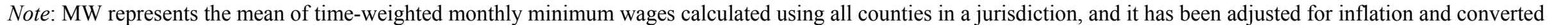
into $2005 \mathrm{RMB}$. 
Table 2 Summary Statistics of Salaried Worker Age 16-59, 2004-2009

\begin{tabular}{lrr}
\hline \multicolumn{1}{c}{ Variable } & Mean & $\begin{array}{c}\text { Standard } \\
\text { Deviation }\end{array}$ \\
\hline Age & & 90.71 \\
Men & 0.55 & 0.50 \\
Earnings (annual, rmb) & 23,716 & 18,811 \\
Years of schooling & 12.87 & 2.74 \\
Han Ethnicity & 0.97 & 0.17 \\
Married with spouse present & 0.88 & 0.32 \\
Local hukou (household registration) & 0.97 & 0.16 \\
Work experience (year) & 21.81 & 10.07 \\
Years of residence & 31.19 & 14.60 \\
\hline
\end{tabular}

Note: The number of observations is 289,002 . Standard deviations are in parentheses. Earnings has been adjusted for inflation and accounted for the differing living costs among provinces by applying the PPP-adjusted deflator developed by Brandt and Holz (2006). 
Table 3 Characteristics of Minimum Wage Standards in China, 2004-2009

\begin{tabular}{|c|c|c|c|}
\hline Variable & $\begin{array}{l}\text { Less than the } \\
\text { Minimum }\end{array}$ & $\begin{array}{c}\text { the } \\
\text { Minimum }\end{array}$ & $\begin{array}{l}\text { Above the } \\
\text { Minimum }\end{array}$ \\
\hline Percent of total (\%) & 6.81 & 1.88 & 91.31 \\
\hline Percent of female $(\%)$ & 62.38 & 63.81 & 43.36 \\
\hline Minimum-to-average wage ratio & $\begin{array}{r}2.35 \\
(4.34)\end{array}$ & $\begin{array}{r}1.00 \\
(0.03)\end{array}$ & $\begin{array}{r}0.36 \\
(0.21)\end{array}$ \\
\hline \multicolumn{4}{|l|}{ Region (\%) } \\
\hline East & 6.43 & 1.84 & 91.73 \\
\hline Central & 6.64 & 1.79 & 91.57 \\
\hline West & 8.61 & 2.23 & 89.17 \\
\hline \multicolumn{4}{|l|}{ Age cohort $(\%)$} \\
\hline Age 16-19 & 41.48 & 5.34 & 53.18 \\
\hline Age $20-29$ & 10.77 & 2.30 & 86.93 \\
\hline Age $30-39$ & 5.77 & 1.62 & 92.61 \\
\hline Age 40-49 & 6.14 & 1.95 & 91.91 \\
\hline Age 50-59 & 6.74 & 1.86 & 91.41 \\
\hline \multicolumn{4}{|l|}{ Educational attainment $(\%)$} \\
\hline Elementary school or below & 19.71 & 4.71 & 75.58 \\
\hline Junior high school & 11.61 & 3.34 & 85.04 \\
\hline High school & 8.12 & 2.35 & 89.53 \\
\hline Vocational school & 5.84 & 1.58 & 92.57 \\
\hline Junior college & 3.52 & 0.96 & 95.52 \\
\hline \multicolumn{4}{|l|}{ Occupation $(\%)$} \\
\hline $\begin{array}{r}\text { Administrative persons of enterprises, state } \\
\text { organs and party organizations }\end{array}$ & 2.54 & 0.55 & 96.91 \\
\hline Professional and technical staff & 2.49 & 0.61 & 96.90 \\
\hline Clerical and related staff & 4.19 & 1.21 & 94.60 \\
\hline Commercial service worker & 14.57 & 4.24 & 81.19 \\
\hline Agricultural worker & 14.85 & 3.89 & 81.26 \\
\hline $\begin{array}{r}\text { Production, transport equipment operator or } \\
\text { related worker }\end{array}$ & 7.34 & 2.30 & 90.37 \\
\hline Other & 17.78 & 4.76 & 77.46 \\
\hline \multicolumn{4}{|l|}{ Industry $(\%)$} \\
\hline Mining & 3.71 & 1.05 & 95.24 \\
\hline Manufacturing & 6.73 & 1.84 & 91.44 \\
\hline Power production and supply & 2.99 & 0.82 & 96.19 \\
\hline Construction & 6.88 & 1.77 & 91.34 \\
\hline Transportation and postal service & 4.74 & 1.23 & 94.03 \\
\hline Information technology & 6.14 & 1.38 & 92.48 \\
\hline Wholesales and retail sales & 12.81 & 3.55 & 83.64 \\
\hline Hotel and restaurant & 12.43 & 3.55 & 84.03 \\
\hline Banking and finance & 3.12 & 0.73 & 96.15 \\
\hline Real estate & 6.80 & 1.65 & 91.55 \\
\hline Leasing and commercial service & 8.01 & 1.84 & 90.15 \\
\hline Scientific Research & 2.49 & 0.47 & 97.04 \\
\hline
\end{tabular}




$\begin{array}{rrrr}\text { Environment and public facility } & 4.72 & 1.40 & 93.88 \\ \text { Housekeeping } & 15.37 & 4.45 & 80.17 \\ \text { Education } & 3.29 & 0.78 & 95.94 \\ \text { Health care } & 4.11 & 1.02 & 94.88 \\ \text { Sports and entertainment } & 4.83 & 0.99 & 94.17 \\ \text { Public service } & 2.87 & 1.06 & 96.07\end{array}$

Note: standard deviations are in parentheses. There are 289,002 salaried workers aged 16-59 in this period. "Less than the Minimum" are workers earning wages at or below $95 \%$ of the minimum wage. Minimum wage workers earn wages above $95 \%$ and up to $105 \%$ of the minimum wage. Above minimum wage workers earn wages above $105 \%$ of the minimum wage. The East includes Liaoning, Beijing, Shandong, Jiangsu, and Guangdong; the Central region includes Heilongjiang, Shanxi, Henan, Anhui, Hubei, and Jiangxi; and the West includes Gansu, Chongqing, Sichuan, and Yunnan. 
Table 4 Marginal Effects of the Minimum Wage on Earnings Differentials, 2004-2009

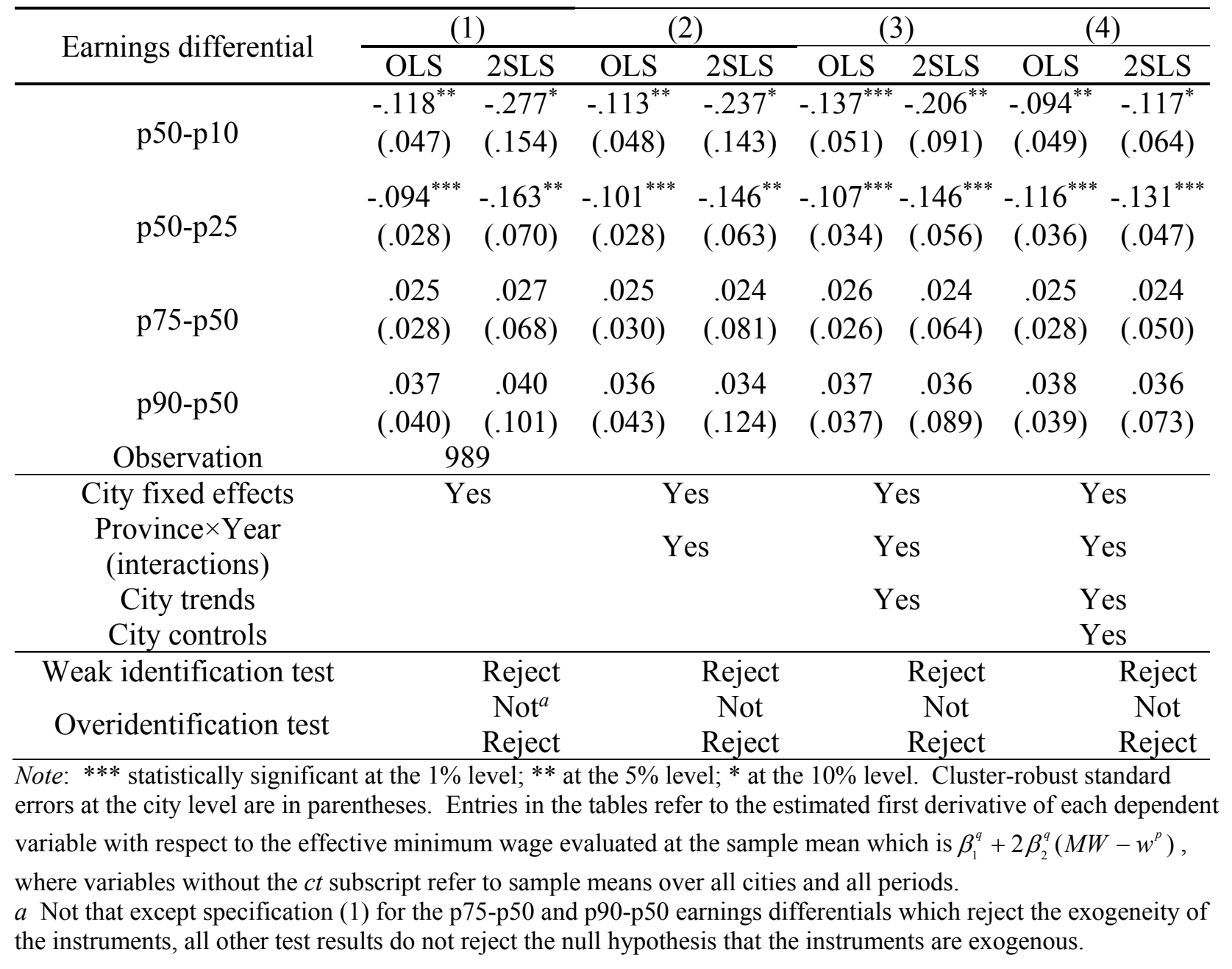


Table 5 Actual and Latent Changes in Earnings Differentials, 2004-2009

\begin{tabular}{|c|c|c|c|c|c|c|c|c|c|c|c|}
\hline \multirow{2}{*}{$\begin{array}{l}\text { Earnings } \\
\text { differential }\end{array}$} & \multirow{2}{*}{ Year } & \multirow{2}{*}{$\begin{array}{l}\text { Log } \\
\text { gap }\end{array}$} & \multirow{2}{*}{$\begin{array}{l}\text { Actual } \\
\text { change }\end{array}$} & \multicolumn{4}{|c|}{$\begin{array}{l}\text { Latent change } \\
\text { (OLS) }\end{array}$} & \multicolumn{4}{|c|}{$\begin{array}{l}\text { Latent change } \\
\text { (2SLS) }\end{array}$} \\
\hline & & & & (1) & (2) & (3) & (4) & (1) & (2) & (3) & (4) \\
\hline p50-p10 & $\begin{array}{l}2004 \\
2009\end{array}$ & $\begin{array}{l}.892 \\
.922\end{array}$ & -.0296 & $\begin{array}{l}-.0415 \\
(.010)\end{array}$ & $\begin{array}{l}-.0396 \\
(.011)\end{array}$ & $\begin{array}{l}-.0375 \\
(.015)\end{array}$ & $\begin{array}{r}-.0335 \\
(.015)\end{array}$ & $\begin{array}{r}-.0495 \\
(.009)\end{array}$ & $\begin{array}{l}-.0436 \\
(.012)\end{array}$ & $\begin{array}{l}-.0395 \\
(.015)\end{array}$ & $\begin{array}{l}-.0360 \\
(.015)\end{array}$ \\
\hline p50-p25 & $\begin{array}{l}2004 \\
2009\end{array}$ & $\begin{array}{l}.463 \\
.468\end{array}$ & -.0047 & $\begin{array}{l}-.0059 \\
(.001)\end{array}$ & $\begin{array}{l}-.0053 \\
(.001)\end{array}$ & $\begin{array}{l}-.0052 \\
(.002)\end{array}$ & $\begin{array}{l}-.0051 \\
(.002)\end{array}$ & $\begin{array}{l}-.0055 \\
(.001)\end{array}$ & $\begin{array}{l}-.0051 \\
(.001)\end{array}$ & $\begin{array}{l}-.0050 \\
(.002)\end{array}$ & $\begin{array}{r}-.0049 \\
(.002)\end{array}$ \\
\hline
\end{tabular}

Note: Actual and latent changes are in log points calculated at city level. Actual change=[log gap(2004)-log gap(2009)]. Marginal effects are bootstrapped and standard deviations associated with the estimates are in parentheses. 


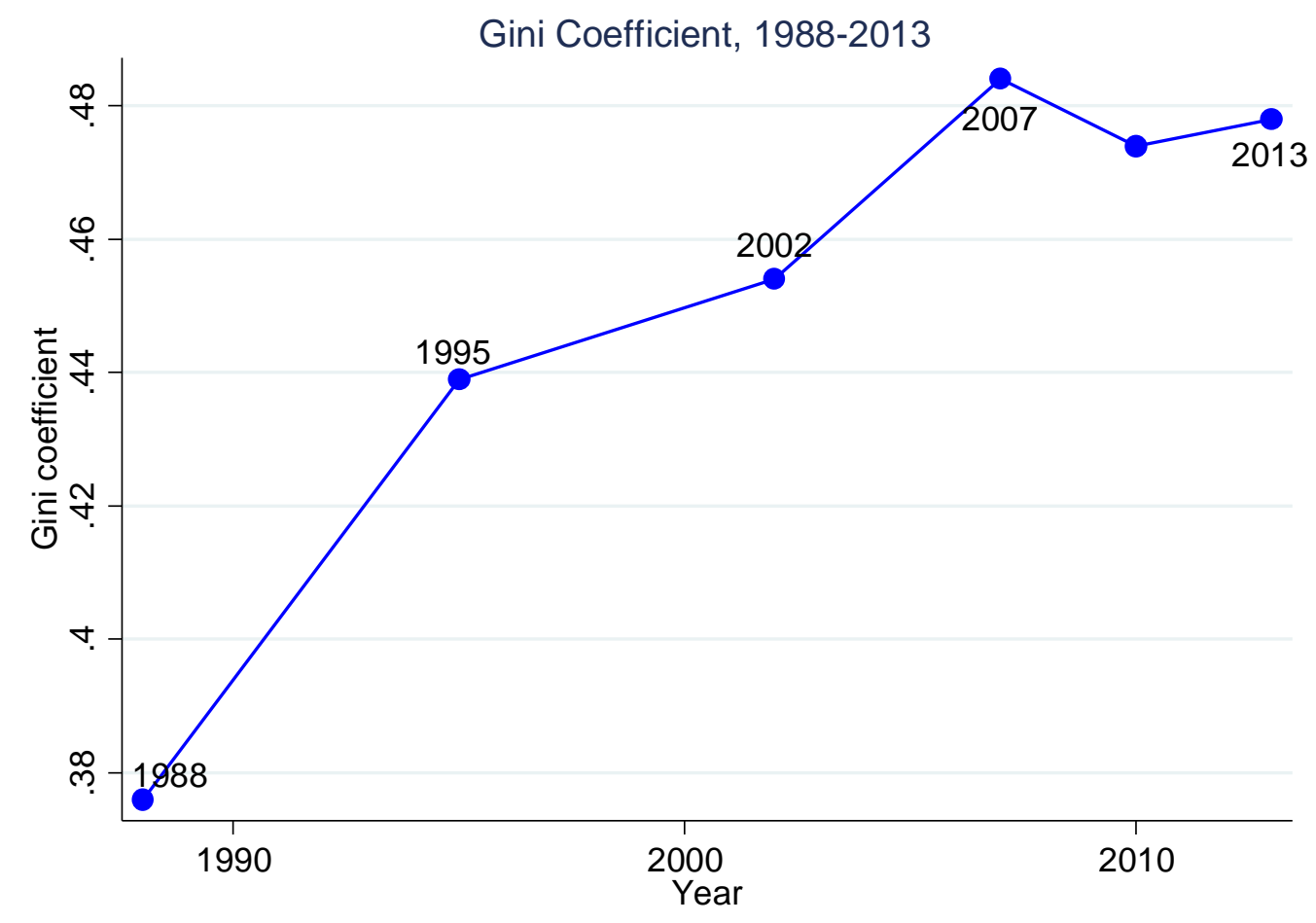

Figure 1 Growing Inequality in China

The NBS of China publishes the official Gini coefficients in 2013 for the first time. The numbers of 2007, 2010 and 2013 are from the NBS website; whereas those of 1988 and 1995 are from Wang (2007), and the number of 2002 is from Li and Luo (2011). 


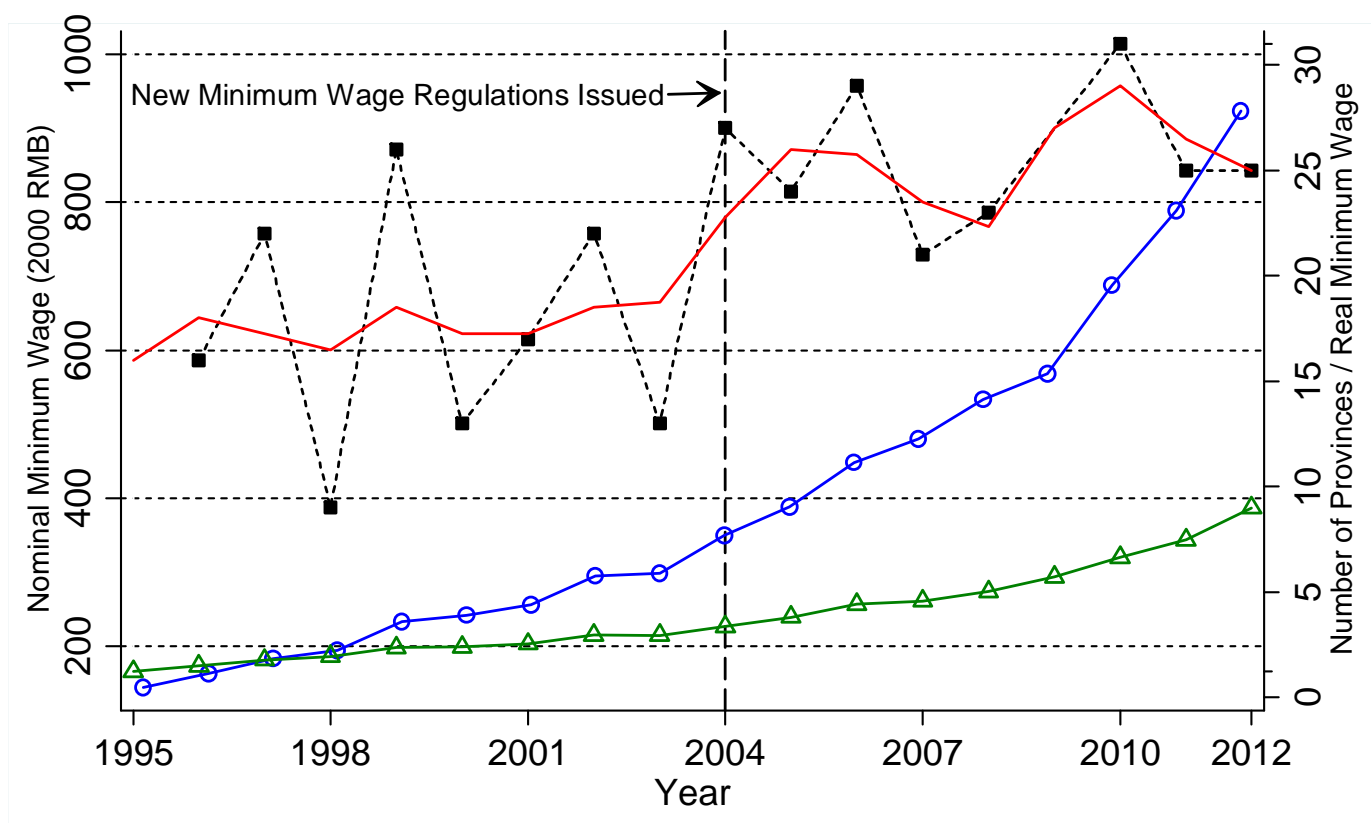

Figure 2 Minimum Wages in China, 1995-2012

Nominal and real minimum wages are adjusted for inflation and expressed in 2000 RMB. 


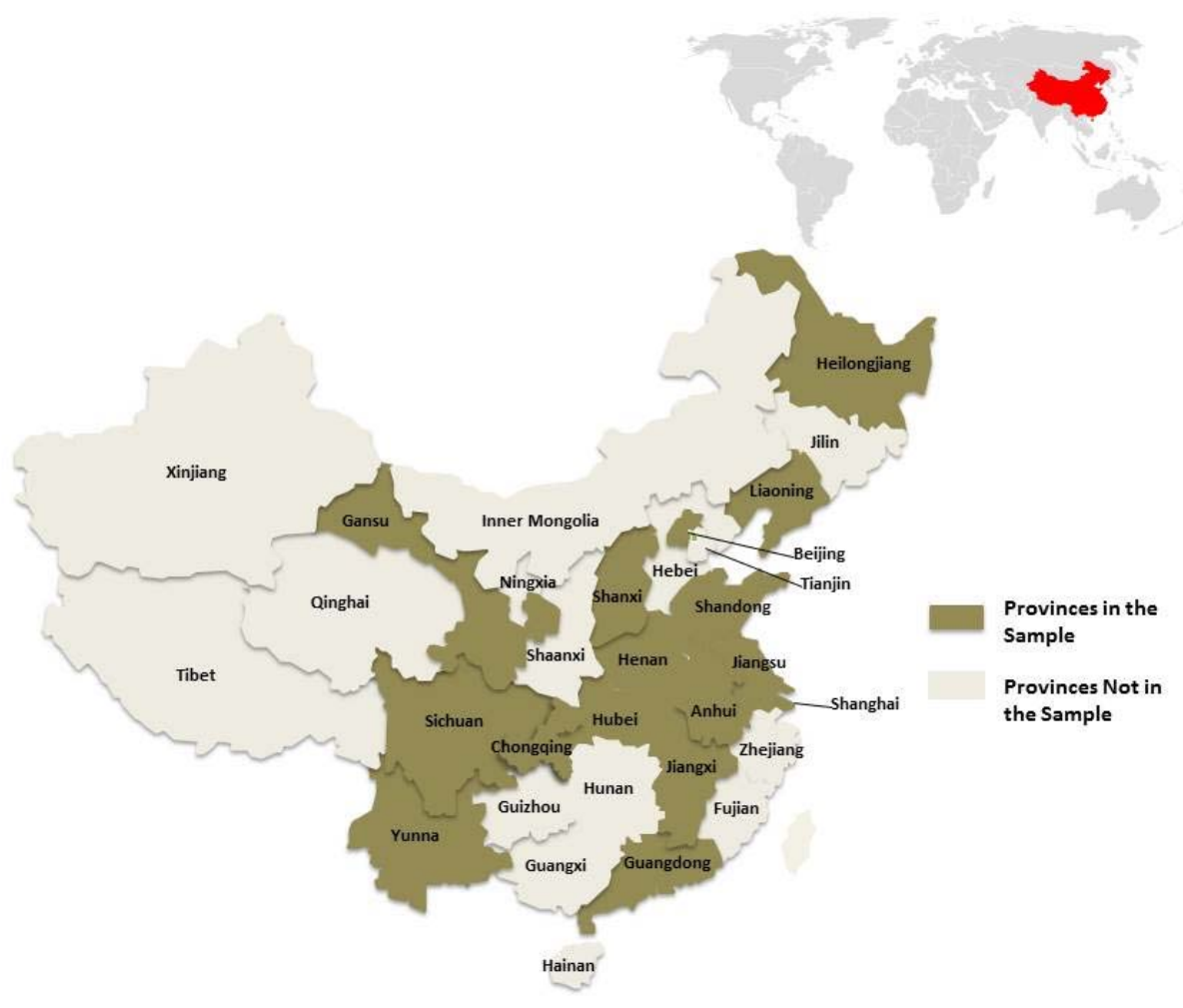

Figure 3 Coverage of Sample Provinces in the Analysis

The data used in the analysis include 16 provinces (darker areas in the map) covering three regions in Mainland China. The East includes Liaoning, Beijing, Shandong, Jiangsu, and Guangdong; the Central region includes Heilongjiang, Shanxi, Henan, Anhui, Hubei, and Jiangxi; and the West includes Gansu, Chongqing, Sichuan, and Yunnan. 

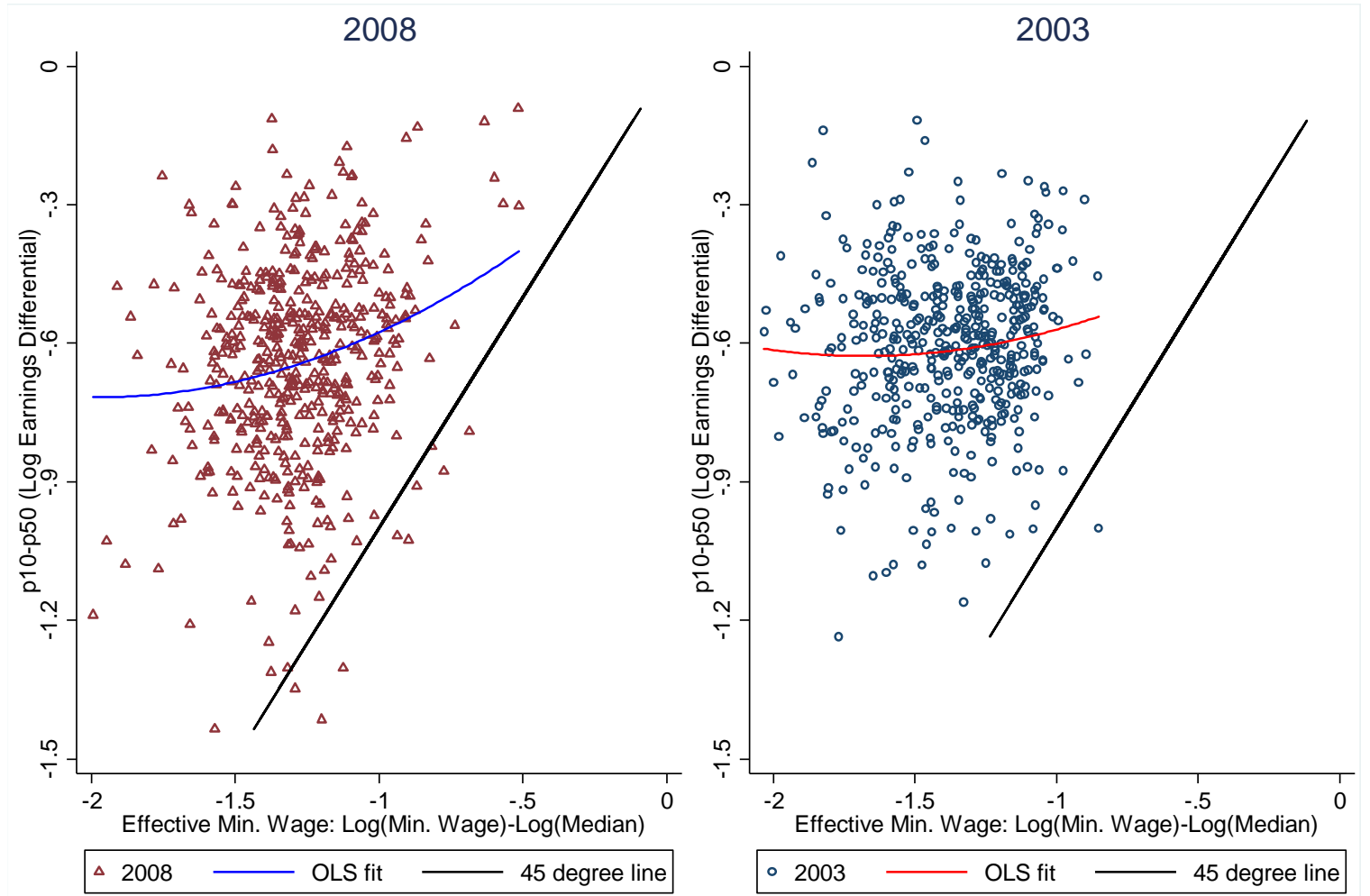

Figure 4 Log Earnings Differential (p10/p50) and the Effective Minimum Wage across cities in 2003 and 2008

The estimated coefficient on the quadratic term for 2008 is statistically significant from zero at the 0.05 level; while it is insignificant for 2003. 